\title{
A New Modified Obstetric Early Warning Score For Prognostication Of Severe Maternal Morbidity
}

\section{Yonghui Xu}

West China Women\'s and Children\'s Hospital: Sichuan University West China Second University Hospital

\section{Sha Zhu}

West China Women\'s and Children\'s Hospital: Sichuan University West China Second University Hospital

\section{Hao Song}

West China Women\'s and Children\'s Hospital: Sichuan University West China Second University Hospital

\section{Xiaoyuan Lian}

West China Women\'s and Children\'s Hospital: Sichuan University West China Second University Hospital

\section{Maoni Zeng}

West China Women\'s and Children\'s Hospital: Sichuan University West China Second University Hospital

\section{$\mathrm{Ji} \mathrm{He}$}

West China Women\'s and Children\'s Hospital: Sichuan University West China Second University Hospital

\section{Lijuan Shu}

West China Women\'s and Children\'s Hospital: Sichuan University West China Second University Hospital

\section{Xingshen Xue}

West China Women\'s and Children\'s Hospital: Sichuan University West China Second University Hospital

\section{Fei Xiao ( $\square$ Xiaofei2021cd@163.com )}

Department of Obstetrics and Gynecology Intensive Care Unit, West China Women's and Children's Hospital, Sichuan University https://orcid.org/0000-0002-6367-7268

\section{Research article}

Keywords: Modified Obstetric Early Warning Score (MOEWS), APACHE II score, maternal morbidity, maternal mortality, intensive care unit (ICU). 
Posted Date: March 3rd, 2022

DOI: https://doi.org/10.21203/rs.3.rs-1238132/v1

License: (c) (i) This work is licensed under a Creative Commons Attribution 4.0 International License. Read Full License 


\section{Abstract}

Background: Maternal mortality is still a major challenge to health systems, while the severe maternal morbidity is the primary reason. Our study was aimed to determine whether severe maternal morbidity is effectively predicted by a newly proposed Modified Obstetric Early Warning Score (MOEWS) in the setting of an obstetric intensive care unit (ICU).

Methods: A retrospective study on pregnant women admitted to the ICU from August 2019 to August 2020 was conducted. The MOEWS was calculated $24 \mathrm{~h}$ before and $24 \mathrm{~h}$ after admission to the ICU, and the highest score was taken as the final value. The aggregate performance of the MOEWS in predicting critically ill patients was evaluated and finally compared with that of the Acute Physiology and Chronic Health Evaluation II (APACHE II) score.

Results: A total of 352 pregnant women were enrolled; 290 cases (82.37\%) with severe maternal morbidity were identified, and 2 of them died $(0.57 \%)$. The MOEWSs of patients with serious obstetric complications were significantly higher than those of patients without serious obstetric complications $[8(6,10)$ vs. $4(2$, 4.25), $\mathrm{z}=-10.347, \mathrm{P}<0.001]$. The sensitivity of the MOEWS was $99.31 \%(95 \% \mathrm{Cl}, 98-100)$, the specificity was $75.81 \%(95 \% \mathrm{Cl}, 63-86)$, the positive predictive value (PPV) was $95.05 \%(95 \% \mathrm{Cl}, 92-97)$ and the negative predictive value (NPV) was $95.92 \%(95 \% \mathrm{Cl}, 86-100)$. The areas under the receiver operator characteristic (ROC) curves of the MOEWS and APACHE II score were 0.917 (95\% Cl: 0.878-0.955, $\mathrm{P}<0.001)$ and 0.697 (95\% Cl: 0.629-0.764), respectively.

Conclusion: The newly proposed MOEWS has an excellent ability to identify potentially at-risk patients early, and it is more effective than APACHE II. It will be a valuable tool for discriminating severe maternal morbidity and ultimately improve maternal safety.

Trial registration: This is not a clinical trial rather a quality improvement project. It will be registered retrospectively.

\section{Introduction}

Maternal mortality is still a major concern for healthcare systems worldwide[1, 2]. Significant improvements in maternal health have been made to date, and the maternal mortality rate has obviously decreased. However, it remains a challenge among vulnerable women, especially in developing countries[3]. Serious obstetric complications are recognized as primary contributors to maternal death $[4,5]$. Thus, the World Health Organization recommends that maternal safety surveillance should focus not only on maternal mortality but also on severe maternal morbidity. Valid identification of highrisk patients will help to improve maternal safety[6, 7].

It is known that obstetric haemorrhage, sepsis, hypertensive disorders, abortion, cardiovascular diseases, amniotic fluid embolism and pulmonary embolism are the most common causes of maternal death[2, 8]. Maternal morbidity and mortality are often preventable. Timely identification of obstetric 
complications can reduce the burden of maternal mortality. However, potentially high-risk pregnant women are often not easily identified [7,9]. The Acute Physiology And Chronic Health Evaluation (APACHE II) score is a widely used prognostic scoring system in nonpregnant populations[10, 11]. Since pregnancy is accompanied by a series of physiological changes, the APACHE II score is not entirely applicable to patients in obstetric ICU settings.

At present, multiple modified obstetric early warning scores are widely used for early identification of critically ill obstetric patients. The Modified Early Obstetric Warning Score (MEOWS)[1, 6, 12], Maternal Early Recognition Criteria (MERC)[13, 14], Modified Early Warning System (MEWS)[3,15], Maternal Early Warning Trigger (MEWT)[16,17], Maternal Early Obstetric Warning System (MEOWS chart)[18, 19], Irish Maternity Early Warning System (IMEWS) [20, 21] and ICNARC Obstetric Early Warning Score (OEWS) [9, 22] are the most common. In 2020, Eugene Tuyishime et al[23] designed a new MEOWS in Rwanda.

The ICNARC OEWS was first compared with the APACHE II score by Monali Khergade et al[22]. The main advantage of all the scoring systems are that they are based on the physiological changes of obstetric patients and do not require any laboratory tests. Most of these predictive models have been verified to recognize at-risk parturients. Nevertheless, there have been no universal standards for obstetric early warning score (EWS) until now, and the parameter settings of each scoring system vary, as do the sensitivity and specificity. Therefore, it makes sense to propose a new modified obstetric early warning score.

The primary objective of this study was to validate the new MOEWS in the prediction of deteriorating maternal condition. The capacity of discernment was assessed by area under receiver operator characteristic (ROC) curves, sensitivity, specificity and predictive value. Furthermore, we compared the predictive ability of the MOEWS with that of the APACHE II score for severe obstetric complications.

\section{Methods}

\section{Aim}

To determine the feasibility of implementing the MOEWS tool in the setting of obstetric ICU

\section{Setting}

Department of Obstetrics and Gynecology, West China Women's and Children's Hospital of Sichuan University is one of the first national key clinical specialty construction, and it is the treatment and referral center of severe pregnant women in western China that conducts about 16,000 deliveries annually.

\section{Study Design}

This was a retrospective study implemented in our hospital from August 2019 to August 2020. A total of 19,438 deliveries occurred during the study period. There were 378 obstetric patients admitted to the dedicated obstetric ICU. All obstetric patients were pregnant and postpartum women within 42 days of delivery, and patients with an ICU stay of at least 24 hours were enrolled. Because multiple patients were 
in critical condition before ICU admission, we assessed the MOEWS 24 hours before and 24 hours after admission to the ICU, and the highest score was taken as the final value. In addition, the APACHE II score was calculated within 24 hours of ICU admission. For calculation of the score, the most abnormal reading of each clinical and laboratory parameter was considered.

The parameters and their numerical values used for the calculation of the MOEWS are shown in Table 1. Measurements of temperature, respiratory rate, and peripheral oxygen saturation, the method of oxygen therapy (nasal catheters, mask, noninvasive ventilator, invasive ventilator), heart rate, blood pressure, and consciousness level (alert, responding to sound or pain and unresponsive) were documented. Regarding the APACHE II score, all laboratory parameters were obtained through venous blood sampling. The partial pressure of oxygen (PaO2) in arterial blood (in $\mathrm{mmHg}$ ) was recorded from the arterial blood gas (ABG) analysis.

Hypertensive disorders in pregnancy, postpartum haemorrhage and pregnancy with heart diseases constitute the main causes of maternal death[24-27]. Women with severe hypertension who underwent treatment with intravenous antihypertensive agents were considered critically ill[28, 29]. Additionally, maladaptation of the cardiovascular system during pregnancy can lead to complications that may put the mother at risk of developing cardiac dysfunction and subsequent heart failure[30]. Consequently, the modified World Health Organization ( $\mathrm{mWHO}$ ) classification of maternal cardiovascular risk was used to assess the maternal risk of cardiac complications $₫$ Attached table $1 \rrbracket$. In this study, patients with cardiovascular diseases whose mWHO risk classification was III or IV were identified as high-risk women[31].

Notably, the vital signs indicating postpartum haemorrhage and cardiac disease were not significantly abnormal in the early stages in many pregnant women, in spite of the vast potential risks for these patients. As a result, 3 points was added to the MOEWS in women confirmed to have severe postpartum haemorrhage or high-risk cardiovascular disease. The definition of severe postpartum haemorrhage was shown in Table 2.

Table 1. Cut-off limits of individual parameters for the MOEWS 


\begin{tabular}{|c|c|c|c|c|c|c|c|}
\hline Score & 3 & 2 & 1 & 0 & 1 & 2 & 3 \\
\hline Temperature $\left({ }^{\circ} \mathrm{C}\right)$ & $\leq 35$ & & $<36$ & $36-37.4$ & $37.5-38$ & $38.1-38.9$ & $\geq 39$ \\
\hline $\begin{array}{l}\text { Respiratory rate }(b \\
\text { eats/min) }\end{array}$ & $<10$ & & $10-11$ & $12-20$ & & $21-29$ & $\geq 30$ \\
\hline $\mathrm{SPO} 2(\%)$ & $\leq 90$ & $91-93$ & $94-95$ & $\geq 96$ & & & \\
\hline Oxygen therapy & $\begin{array}{l}\text { Mask or } \\
\text { above }\end{array}$ & $\begin{array}{l}\text { Nasal } \\
\text { catheter }\end{array}$ & & Room air & & & \\
\hline $\begin{array}{l}\text { Heart rate } \\
\text { (beats/min) }\end{array}$ & $<50$ & $50-59$ & & $60-99$ & $100-109$ & $110-129$ & $\geq 130$ \\
\hline $\begin{array}{l}\text { Systolic blood pres } \\
\text { sure }(\mathrm{mmHg})\end{array}$ & $<90$ & & $90-99$ & $100-139$ & $140-149$ & $150-159$ & $\geq 160$ \\
\hline $\begin{array}{l}\text { Diastolic blood } \\
\text { pressure (mmHg) }\end{array}$ & & & $\leq 45$ & $46-89$ & $90-99$ & $100-109$ & $\geq 110$ \\
\hline Consciousness level & & & & Alert & & & $\begin{array}{l}\text { Not } \\
\text { alert }\end{array}$ \\
\hline
\end{tabular}

For the women with severe postpartum haemorrhage or high-risk cardiovascular disease (mWHO III or IV)*, 3 points was added to the total score.

Recommended clinical reaction: The critical care system changes colour based on the score of each parameter to alert the ICU team to initiate a clinical response, with scores of 3 turning red and 2 turning yellow. When the total MOEWS $\leq 2$, the current plan is maintained; when the MOEWS $=3-4$, the observations are repeated; when the MOEWS $\geq 5$ or a single parameter score is $\geq 3$, the patient is admitted to the ICU. *The details were shown in Table 2 and the attached table1.

The study endpoint was severe maternal morbidity, while the secondary outcomes were the length of ICU stay, age, gestational age, the number of requirements for ventilation, vasopressors, intravenous antihypertensive drugs, transfusion, hysterectomy, arterial embolization, haemodialysis and extracorporeal membrane oxygenation (ECMO). The relative definitions of maternal morbidity are shown in Table 2.

Table 2: Diagnostic criteria of severe obstetric morbidity 
Obstetric morbidity Diagnostic criteria

Pre-eclampsia[19] $\quad \mathrm{SBP} \geq 160 \mathrm{mmHg}$, or $\mathrm{DBP} \geq 110 \mathrm{mmHg}$ plus proteinuria $\geq 0.3 \mathrm{~g}$. day-1 (+2 dipstick) or hypertension $(\geq 140 / 90 \mathrm{mmHg}$ ) and proteinuria with at least one of the following: headache; visual disturbance; epigastric pain; clonus; platelet count $\leq 100.109-1$ ); AST $>50$ iu. -1 ; $\mathrm{Cr}>100$ umol.I -1 ; or $\mathrm{CrCl}<80.8$ ml.min-1

Eclampsia[29]

Severe preeclampsia characterized by sudden onset of generalized tonicclonic seizures

Obstetric

haemorrhage[19]

Documented estimated blood loss $\geq 1500 \mathrm{ml}$, drop in haemoglobin concentration $>3 \mathrm{~g} / \mathrm{dl}$ or need for blood transfusion

Severe postpartum

haemorrhage[14, 32]
Documented estimated blood loss $\geq 2000 \mathrm{ml}$, need for blood transfusion of at least $3 \mathrm{U}$, or hysterectomy, with or without radiological embolization of uterine arteries
Suspected

infection[19]

Shock[18]
Clinically suspected focus of infection \pm positive laboratory culture, treated with antibiotics (excluding commensals and antibiotic prophylaxis)

Persistent severe hypotension defined as systolic blood pressure $<90$ $\mathrm{mmHg}$ for $60 \mathrm{~min}$ or decreased by $40 \mathrm{mmHg}$

Breathlessness, crepitation requiring diuretics
Pulmonary

oedema[19]

Thromboembolism[12]

Diabetic

ketoacidosis[19]

Intracranial tumour[19]

Status epilepticus[19]

Other serious medical conditions[19, 33-35]
CTPA confirmed pulmonary embolism, venous thrombosis in the pelvic region, deep venous thrombosis in the extremities or sinus thrombosis

SBP, systolic blood pressure; DBP, diastolic blood pressure; AST, aspartate aminotransferase; $\mathrm{Cr}$, creatinine; $\mathrm{CrCL}$, creatinine clearance; $\mathrm{CTPA}$, computed tomography pulmonary angiogram; MRI, magnetic resonance imaging.

\section{Statistical analysis}

The results were tabulated and subjected to statistical analysis using Statistical Package for Social Sciences (SPSS) version 25.0. ROC curves were used to determine the area under the curve of various scores for predicting severe morbidity. Sensitivity, specificity, positive predictive values (PPVs), and negative predictive values (NPVs) were calculated. For all statistical tests, we regarded a value of $p<0.05$ as statistically significant.

\section{Results}


A total of 378 pregnant women were admitted to the ICU, and 352 patients were enrolled. A total of 290 patients $(82.37 \%)$ experienced serious complications, and 2 of them died $(0.57 \%)$. One of these two patients died of pulmonary embolism, and another died of severe pulmonary hypertension. The most frequent causes of ICU admission were hypertensive disorders $(108,30.68 \%)$, followed by cardiovascular disease $(94,26.7 \%)$, obstetric haemorrhage $(61,17.33 \%)$, suspected infection $(22,6.25 \%)$ and acute pulmonary oedema $(14,3.98 \%)$ (Table 3$)$. 
Table 3

Distribution of maternal morbidity.

\begin{tabular}{|c|c|c|}
\hline Indications for admission to ICU & $\begin{array}{l}\text { Frequency }(\mathrm{n} \\
=352)\end{array}$ & $\begin{array}{l}\text { Percentage } \\
(\%)\end{array}$ \\
\hline Hypertensive disorders in pregnancy & 108 & 30.68 \\
\hline Cardiovascular disease & 94 & 26.7 \\
\hline Haemorrhage & 61 & 17.33 \\
\hline Suspected infection & 22 & 6.25 \\
\hline Acute pulmonary oedema & 14 & 3.98 \\
\hline Pulmonary embolus & 6 & 1.7 \\
\hline $\begin{array}{l}\text { Liver disease (liver failure, severe hepatitis, acute fatty liver of } \\
\text { pregnancy, hepatitis B cirrhosis) }\end{array}$ & 6 & 1.7 \\
\hline Systemic lupus erythematosus (SLE) & 6 & 1.7 \\
\hline Acute pancreatitis & 2 & 0.57 \\
\hline Acute appendicitis & 2 & 0.57 \\
\hline Anaphylaxis & 3 & 0.85 \\
\hline Gastrointestinal haemorrhage & 2 & 0.57 \\
\hline Malignancy & 5 & 1.42 \\
\hline Diabetic ketoacidosis & 1 & 0.28 \\
\hline Hyperthyroidism crisis & 2 & 0.57 \\
\hline Other medical disorders & 26 & 7.39 \\
\hline Neurological diseases & 5 & 1.42 \\
\hline Respiratory diseases & 3 & 0.85 \\
\hline Blood disease & 4 & 1.14 \\
\hline Deep vein thrombosis (DVT) & 2 & 0.57 \\
\hline Ranal transplantation & 1 & 0.28 \\
\hline Others & 11 & 3.13 \\
\hline
\end{tabular}

Good risk stratification ability was demonstrated by the MOEWS. According to our investigation, shock occurred in 9 pregnant women, heart failure occurred in 33 patients, and sepsis occurred in 9 patients. Meanwhile, 85 cases were treated with intravenous antihypertensive drugs for hypertensive disorders, of which 2 patients developed eclampsia and 1 experienced hypertensive crisis. Forty patients were complicated with severe postpartum haemorrhage, 22 of whom underwent hysterectomy or arterial 
embolization. For the women with serious arrhythmia, 7 underwent temporary pacemaker installation or external direct current cardioversion. Noninvasive or invasive ventilation and transfusion were mostly used in patients with high MOEWSs, as were haemodialysis and ECMO, especially in the MOEWS $\geq 7$ group (Figures1 and 2).

The MOEWS was correlated with the length of ICU stay and gestational age. According to our investigation, the median MOEWS and APACHE II score were $7(5,9.75)$ and $4(2,6)$, respectively. In the high-risk group (score $\geq 5$ ), the median APACHE II score $[4(2,6)]$ and the length of ICU stay $₫ 4(2,4)$ 『were greater than those of the low-risk (score of 0-2) and moderate-risk (score of 3-4) groups, while the gestational age $\{\varangle 34 \pm 2.5(31 \pm 1,36 \pm 4) \varangle\}$ was shorter $(p<0.001)$. However, there was no statistically significant difference between the low-risk and moderate-risk groups. Furthermore, the median age was not significantly different among all the groups ( $p>0.05$ ) (Table 4$)$.

Table 4

Correlation of the MOEWS and APACHE II score with secondary outcomes.

\begin{tabular}{|c|c|c|c|c|c|c|}
\hline $\begin{array}{l}\text { MOEWS } \\
\text { score }\end{array}$ & Total & $\begin{array}{l}\text { Critically } \\
\text { ill }\end{array}$ & $\begin{array}{l}\text { APACHE II } \\
\text { score }\end{array}$ & $\begin{array}{l}\text { Length of ICU stay } \\
\text { (days) }\end{array}$ & $\begin{array}{l}\text { Age } \\
\text { (years) }\end{array}$ & $\begin{array}{l}\text { Gestational age } \\
\text { (weeks) }\end{array}$ \\
\hline $0-2$ & 16 & 2 & $2(0.5,3)$ & $2(1,2)$ & $\begin{array}{l}31.5(29.3 \\
36.0)\end{array}$ & $\begin{array}{l}38 \pm 1.5(36 \pm 0 \\
38 \pm 4)\end{array}$ \\
\hline $3-4$ & 47 & 14 & $3(2,5)$ & $2(1,2)$ & $\begin{array}{l}31.0(27.0 \\
34.0)\end{array}$ & $\begin{array}{l}36 \pm 2.0(33 \pm 1 \\
38 \pm 5)\end{array}$ \\
\hline$\geq 5$ & 289 & 274 & $4(2,6)^{\star}$ & $4(2,4)$ * & $\begin{array}{l}32.0(28.0 \\
35.0)\end{array}$ & $\begin{array}{l}34 \pm 2.5(31 \pm 1 \\
36 \pm 4) *\end{array}$ \\
\hline $\mathrm{H}$ value & & & 18.068 & 18.797 & 0.931 & $18.504 \pm 1.667$ \\
\hline$P$ value & & & 0.000 & 0.000 & 0.628 & 0.000 \\
\hline
\end{tabular}

The median score of MOEWS and APACHE II in group of critically ill is higher than the group of not critically ill $(P<0.001)$ (Table 5). Furthermore, the AUROC of the MOEWS was $0.917(95 \% \mathrm{Cl}, 0.878-0.955$, $\mathrm{P}<0.001)$. A cut-off of $>4$ had a sensitivity of $99.31 \%(95 \% \mathrm{Cl}, 98-100)$, a specificity of $75.81 \%(95 \% \mathrm{Cl}, 63-$ 86), a PPV of $95.05 \%(95 \% \mathrm{Cl}, 92-97)$ and an NPV of $95.92 \%(95 \% \mathrm{Cl}, 86-100)$. In addition, the AUROC of the APACHE II score was $0.697(95 \% \mathrm{Cl}, 0.629-0.764, \mathrm{P}<0.001)$. When the cut-off was $\geq 10$, the sensitivity was $10.34 \%$ ( $95 \% \mathrm{Cl}, 7-14)$, the specificity was $98.39 \%$ (95\% Cl, $91-100)$, the PPV was $96.77 \%(95 \% \mathrm{Cl}$, 83$100)$, the NPV was $8.08 \%(95 \% \mathrm{Cl}, 15-24)$. The predicted maternal mortality of APACHE II is $8.43 \%(4.25$, $24.18) \varangle 95 \% \mathrm{Cl}, 8.77-25.89 \rrbracket$ which is higher than the observer maternal mortality (0.57\%) (Table 6 and Figure 3). 
Table 5

The comparison of MOEWS and APCHEll score between critically ill and not critically ill groups

\begin{tabular}{|c|c|c|c|c|c|}
\hline Score & Median & Not critically ill (95\% Cl) & $\begin{array}{l}\text { Critically ill } \\
(95 \% \mathrm{Cl})\end{array}$ & $Z$ value & $P$ value \\
\hline MOEWS & $7(5,9.75)$ & $4(3,4.25)$ & $8(6,10)$ * & -10.347 & 0.000 \\
\hline \multirow[t]{3}{*}{ APACHE II } & $4(2,6)$ & $(3.38-4.24)$ & $(7.93-8.68)$ & -4.926 & 0.000 \\
\hline & & $2(2,4)$ & $4(2,6)$ * & & \\
\hline & & $(2.25-3.26)$ & $(4.47-5.43)$ & & \\
\hline
\end{tabular}

Table 6

Validity of the MOEWS and APACHE II score to predict maternal morbidity.

\begin{tabular}{|c|c|c|c|c|c|c|c|}
\hline Score & $\begin{array}{l}\text { Cut- } \\
\text { off }\end{array}$ & $\begin{array}{l}\text { AUROC } \\
(95 \% \mathrm{Cl})\end{array}$ & $\begin{array}{l}\text { Sensitivity } \\
(95 \% \mathrm{Cl})\end{array}$ & $\begin{array}{l}\text { Specificity } \\
(95 \% \mathrm{Cl})\end{array}$ & $\begin{array}{l}\text { PPV } \\
\text { (95\% } \\
\text { Cl) }\end{array}$ & $\begin{array}{l}\text { NPV } \\
(95 \% \\
\text { Cl) }\end{array}$ & $\begin{array}{l}\text { Predicted } \\
\text { maternal } \\
\text { mortality } \\
(95 \% \mathrm{Cl})\end{array}$ \\
\hline MOEWS & $\geq 4$ & $\begin{array}{l}0.917 \\
(0.878- \\
0.955)\end{array}$ & $\begin{array}{l}99.31 \% \\
(98-100)\end{array}$ & $\begin{array}{l}75.81 \% \\
(63-86)\end{array}$ & $\begin{array}{l}95.05 \% \\
(92-97)\end{array}$ & $\begin{array}{l}95.92 \% \\
(86- \\
100)\end{array}$ & \\
\hline $\begin{array}{l}\text { APACHE } \\
\text { II }\end{array}$ & $\geq 10$ & $\begin{array}{l}0.697^{\star} \\
(0.629- \\
0.764)\end{array}$ & $\begin{array}{l}10.34 \% \\
(7-14)\end{array}$ & $\begin{array}{l}98.39 \% \\
(91-100)\end{array}$ & $\begin{array}{l}96.77 \% \\
(83- \\
100)\end{array}$ & $\begin{array}{l}8.08 \% \\
(15-24)\end{array}$ & $\begin{array}{l}8.43 \%(4.25, \\
24.18) \\
(8.77-25.89)\end{array}$ \\
\hline$P$ value & & 0.000 & & & & & \\
\hline
\end{tabular}

The predicted maternal mortality of APACHE II score is shown as M (P25, P75); * indicates statistical significance.

\section{Discussion}

The MOEWS is a simple bedside screening tool for maternal morbidity. This is the first study to evaluate the MOEWS both 24 hours before and 24 hours after admission to the ICU. We found that patients with critical complications could be screened early to a great extent.

Our results demonstrated an association between the MOEWS and maternal morbidity. The most common indication for admission to the obstetric ICU was preeclampsia, and most cases required treatment with intravenous antihypertensive drugs; the next most common indications for admission were cardiovascular diseases, obstetric haemorrhage and suspected infection (Tables 2 and 3). Shock, 
heart failure, severe postpartum haemorrhage, sepsis, hypertensive crisis and eclampsia were highly related to maternal mortality.

The good risk stratification ability of the MOEWS was elucidated in our study. The risk of severe morbidity increased as the MOEWS increased. Therefore, we classified patients with a MOEWS $\geq 5$ in the high-risk group, while the patients with a MOEWS $\geq 7$ were classified as extremely high-risk and had a mortality rate of $0.07 \%$. The others were divided into low-risk (MOEWS $=0-2$ ) and moderate-risk (MOEWS $=3-4$ ) groups, respectively, based on the proportion of patients with serious complications. Simultaneously, the use of advanced life support, such as noninvasive or invasive ventilation, temporary pacemaker or cardioversion, haemodialysis and ECMO, increased as the MOEWS increased (Figure 1,2). As a result, we recommend that patients with a MOEWS $\geq 5$ or a single parameter score $\geq 3$ be admitted to the ICU.

Overall, the MOEWS was found to significantly correlate with length of ICU stay and gestational age. Patients with a high MOEWS tended to have longer ICU stays and fewer gestational weeks than the lowor moderate-risk group (Tables 4, 5). Moreover, good discrimination by the MOEWS was demonstrated by an area under the ROC curve of 0.917 (95\% Cl, 0.878-0.955), as well as by its high sensitivity (99.31\%), specificity (75.81\%), PPV (95.05\%) and NPV (95.92\%). For this result, two main courses were analysed. First, the endpoint of the study was maternal morbidity rather than mortality, since maternal mortality is rare. Second, 3 points was added to the MOEWS for women who were confirmed to have severe postpartum haemorrhage and high-risk cardiovascular disease (mWHO III and IV) to identify those potentially at-risk patients earlier.

Notably, the APACHE II score increased as the MOEWS increased. However, most APACHE II scores in this study were less than 10 points, in spite of the patients with severe conditions. As a result, both the AUROC and the sensitivity of the APACHE II score were obviously reduced when the cut-off was $\geq 10$ (Table 4, 5, 6). However, APACHE II score tends to overpredict the maternal mortalities, and this was also observed in the previous studies $[10,22,36,37]$. We analysed this result, which may be related to the different backgrounds of the ICU. There were some differences between the standards of admission to the obstetric-specific ICU for pregnant women and the general hospital ICU. Obstetric patients in the general hospital ICU may be more critical overall. On the other hand, this indicates that the APACHE II score may not be entirely applicable for predicting severe maternal morbidity in the setting of a dedicated obstetric ICU.

Generally, our study shows that the MOEWS is an effective predictor of maternal morbidity. It is simple and less time-consuming since it is calculated on the basis of bedside parameters. For cardiovascular diseases, the information needed for risk assessment can be obtained from the medical history or emergency bedside ultrasound.

Several limitations should be considered when interpreting the results of this study. First, our study was only conducted in our hospital, and the results may not be completely applicable to other hospital settings. In addition, it was a retrospective analysis, and the sample size was small. Additional prospective studies are required to validate the conclusions. 


\section{Conclusion}

The MOEWS tool is feasible and acceptable in dedicated obstetric ICUs. The implementation of the MOEWS may contribute to preventing progressive maternal morbidity by improving the identification of deteriorating patients early. Similarly, both the quality of care and maternal safety can be improved to a certain extent. Nonetheless, successful implementation of the MOEWS needs further study to evaluate the efficiency of prediction for maternal morbidity in other ICU settings.

\section{Abbreviations}

MOEWS: modified obstetric early warning score; ICU: intensive care unit; APACHE II: Acute Physiology and Chronic Health Evaluation II; PPV: positive predictive value; NPV: negative predictive value; AUROC: area under receiver operator characteristic; PaO2: partial pressure of oxygen; ABG: arterial blood gas; ECMO: extracorporeal membrane oxygenation; mWHO: Modified World Health Organization.

\section{Declarations}

\section{Ethics approval and consent to participate}

This is a retrospective study, approval was granted by the Ethics Committee of West China Women's and Children's Hospital of Sichuan University.

\section{Consent for publication}

Not applicable.

\section{Availability of data and materials}

The datasets used and/or analysed during the current study are available from the corresponding author on reasonable request.

\section{Competing interests}

The authors declare that they have no competing interests.

\section{Funding}

None.

\section{Authors' contributions}

Fei Xiao, Yonghui Xu: Study design, Results interpretation, Data analysis.

XingSheng Xue: Results interpretation. 
Yonghui Xu: Data cleaning and Manuscript writing.

Other authors: Data collection.

All authors critically reviewed and approved the final manuscript.

\section{Acknowledgements}

The authors are grateful to all the doctors who used the MOEWS tool in the Department of Obstetrics and Gynecology Intensive Care Unit of West China Women's and Children's Hospital.

\section{Conflict of interest statement}

All of the authors declare that they have no competing interests.

\section{References}

1. Mander R, Smith GD. Saving Mothers' Lives (formerly Why Mothers die): reviewing maternal deaths to make motherhood safer 2003-2005. Midwifery. 2008;24:8-12.

https://doi.org/10.1016/j.midw.2008.01.008.

2. Dzakpasu S, Deb-Rinker P, Arbour L, et al. Severe maternal morbidity surveillance: Monitoring pregnant women at high risk for prolonged hospitalisation and death. Paediatr Perinat Epidemiol. 2020;34:427-39. https://doi.org/10.1111/ppe.12574.

3. Blumenthal E, Hooshvar N, McQuade M, McNulty J. (2019) A Validation Study of Maternal Early Warning Systems: A Retrospective Cohort Study. Am J Perinatol 36:. https://doi.org/10.1055/s-00391681097.

4. Say L, Chou D, Gemmill A, et al. Global causes of maternal death: a WHO systematic analysis. Lancet Glob Heal. 2014;2:e323-33. https://doi.org/10.1016/S2214-109X(14)70227-X.

5. Schaap T, Bloemenkamp K, Deneux-Tharaux C, et al. Defining definitions: a Delphi study to develop a core outcome set for conditions of severe maternal morbidity. BJOG. 2019;126:394-401. https://doi.org/10.1111/1471-0528.14833.

6. Ryan HM, Jones MA, Payne BA, et al (2017) Validating the Performance of the Modified Early Obstetric Warning System Multivariable Model to Predict Maternal Intensive Care Unit Admission. J Obstet Gynaecol Canada JOGC = J d'obstetrique Gynecol du Canada JOGC 39:728-733.e3. https://doi.org/10.1016/j.jogc.2017.01.028.

7. Mhyre JM, D'Oria R, Hameed AB, et al. The maternal early warning criteria: a proposal from the national partnership for maternal safety. Obstet Gynecol. 2014;124:782-6. https://doi.org/10.1097/AOG.0000000000000480.

8. Zuckerwise LC, Lipkind HS. Maternal early warning systems-Towards reducing preventable maternal mortality and severe maternal morbidity through improved clinical surveillance and responsiveness. Semin Perinatol. 2017;41:161-5. https://doi.org/10.1053/j.semperi.2017.03.005. 
9. Carle C, Alexander P, Columb M, Johal J. Design and internal validation of an obstetric early warning score: secondary analysis of the Intensive Care National Audit and Research Centre Case Mix Programme database. Anaesthesia. 2013;68:354-67. https://doi.org/10.1111/anae.12180.

10. Lee JH, Hwang SY, Kim HR, et al. Effectiveness of the sequential organ failure assessment, acute physiology and chronic health evaluation II, and simplified acute physiology score II prognostic scoring systems in paraquat-poisoned patients in the intensive care unit. Hum Exp Toxicol. 2017;36:431-7. https://doi.org/10.1177/0960327116657602.

11. Draper EA, Wagner DP, Zimmerman JE. APACHE II: A severity of disease classification system. Crit Care Med. 1985;13:818_829.

12. Hoppu S, Hannola K, Mennander S, et al. Routine Bedside Use of Obstetric Early Warning System in the Postnatal Ward to Identify Maternal Morbidity Among High-Risk Women. J Patient Saf. 2020. https://doi.org/10.1097/PTS.0000000000000766.

13. Klumpner TT, Kountanis JA, Langen ES, et al. Use of a novel electronic maternal surveillance system to generate automated alerts on the labor and delivery unit. BMC Anesthesiol. 2018;18:78. https://doi.org/10.1186/s12871-018-0540-6.

14. Klumpner TT, Kountanis JA, Meyer SR, et al. Use of a Novel Electronic Maternal Surveillance System and the Maternal Early Warning Criteria to Detect Severe Postpartum Hemorrhage. Anesth Analg. 2020;131:857-65. https://doi.org/10.1213/ANE.0000000000004605.

15. Friedman AM, Campbell ML, Kline CR, et al. Implementing Obstetric Early Warning Systems. AJP Rep. 2018;8:e79-84. https://doi.org/10.1055/s-0038-1641569.

16. Blumenthal EA, Hooshvar N, Tancioco V, et al. Implementation and Evaluation of an Electronic Maternal Early Warning Trigger Tool to Reduce Maternal Morbidity. Am J Perinatol. 2021;38:869-79. https://doi.org/10.1055/s-0040-1721715.

17. Shields LE, Wiesner S, Klein C, et al (2016) Use of Maternal Early Warning Trigger tool reduces maternal morbidity. Am J Obstet Gynecol 214:527.e1-527.e6. https://doi.org/10.1016/j.ajog.2016.01.154.

18. Singh A, Guleria K, Vaid NB, Jain S. Evaluation of maternal early obstetric warning system (MEOWS chart) as a predictor of obstetric morbidity: a prospective observational study. Eur J Obstet Gynecol Reprod Biol. 2016;207:11-7. https://doi.org/10.1016/j.ejogrb.2016.09.014.

19. Singh S, McGlennan A, England A, Simons R. A validation study of the CEMACH recommended modified early obstetric warning system (MEOWS). Anaesthesia. 2012;67:12-8. https://doi.org/10.1111/j.1365-2044.2011.06896.x.

20. Maguire PJ, O'Higgins A, Power K, Turner MJ. The Irish Maternity Early Warning System (IMEWS). Ir Med J. 2014;107:309.

21. Nair S, Spring A, Dockrell L, Mac Colgain S. Irish Maternal Early Warning Score. Ir J Med Sci. 2020;189:229-35. https://doi.org/10.1007/s11845-019-02028-1.

22. Khergade M, Suri J, Bharti R, et al. Obstetric Early Warning Score for Prognostication of Critically III Obstetric Patient. Indian J Crit care Med peer-reviewed. Off Publ Indian Soc Crit Care Med. 
2020;24:398-403. https://doi.org/10.5005/jp-journals-10071-23453.

23. Tuyishime E, Ingabire H, Mvukiyehe JP, et al. Implementing the Risk Identification (RI) and Modified Early Obstetric Warning Signs (MEOWS) tool in district hospitals in Rwanda: a cross-sectional study. BMC Pregnancy Childbirth. 2020;20:568. https://doi.org/10.1186/s12884-020-03187-1.

24. Reale SC, Leffert LR, Farber MK. Update on Obstetric Hemorrhage. Curr Anesthesiol Rep. 2019;9:608. https://doi.org/10.1007/s40140-019-00311-6.

25. Gillissen A, van den Akker T, Caram-Deelder C, et al. Predictive value of a bleeding score for postpartum hemorrhage. Res Pract Thromb Haemost. 2019;3:277-84. https://doi.org/10.1002/rth2.12194.

26. Liu C-N, Yu F-B, Xu Y-Z, et al. Prevalence and risk factors of severe postpartum hemorrhage: a retrospective cohort study. BMC Pregnancy Childbirth. 2021;21:332. https://doi.org/10.1186/s12884021-03818-1.

27. Gonzalez-Brown V, Schneider P. Prevention of postpartum hemorrhage. Semin Fetal Neonatal Med. 2020;25:101129. https://doi.org/10.1016/j.siny.2020.101129.

28. Sinkey RG, Battarbee AN, Bello NA, et al. Prevention, Diagnosis, and Management of Hypertensive Disorders of Pregnancy: a Comparison of International Guidelines. Curr Hypertens Rep. 2020;22:66. https://doi.org/10.1007/s11906-020-01082-w.

29. Clinical Guidelines - Queensland Health Q. (2017) Maternity and Neonatal Clinical Guideline. QueensI Heal 1-39.

30. Aryan L, Medzikovic L, Umar S, Eghbali M. Pregnancy-associated cardiac dysfunction and the regulatory role of microRNAs. Biol Sex Differ. 2020;11:14. https://doi.org/10.1186/s13293-02000292-w.

31. Regitz-Zagrosek V, Roos-Hesselink JW, Bauersachs J, et al. 2018 ESC Guidelines for the management of cardiovascular diseases during pregnancy. Kardiol Pol. 2019;77:245-326. https://doi.org/10.5603/KP.2019.0049.

32. Henriquez DDCA, Gillissen A, Smith SM, et al. Clinical characteristics of women captured by extending the definition of severe postpartum haemorrhage with "refractoriness to treatment": a cohort study. BMC Pregnancy Childbirth. 2019;19:361. https://doi.org/10.1186/s12884-019-2499-9.

33. Cruciat G, Nemeti G, Goidescu I, et al. Hypertriglyceridemia triggered acute pancreatitis in pregnancy diagnostic approach, management and follow-up care. Lipids Health Dis. 2020;19:2. https://doi.org/10.1186/s12944-019-1180-7.

34. Segev L, Segev Y, Rayman S, et al. Acute Appendicitis During Pregnancy: Different from the Nonpregnant State? World J Surg. 2017;41:75-81. https://doi.org/10.1007/s00268-016-3731-7.

35. Lim E, Mouyis M, MacKillop L. (2021) Liver diseases in pregnancy. Clin Med (Northfield II) 21:e441 LP-e445. https://doi.org/10.7861/clinmed.2021-0497.

36. Suri J, Kumar R, Gupta A, et al. A Prospective Study of Clinical Characteristics and Interventions Required in Critically III Obstetric Patients. Indian J Crit Care Med. 2020;24:677-82. https://doi.org/10.5005/jp-journals-10071-23519. 
37. Ryan HM, Sharma S, Magee LA, et al. The Usefulness of the APACHE II Score in Obstetric Critical Care: A Structured Review. J Obstet Gynaecol Canada JOGC = J d'obstetrique. Gynecol du Canada JOGC. 2016;38:909-18. https://doi.org/10.1016/j.jogc.2016.06.013

\section{Figures}

Figure 1

Legend not included with this version.

Figure 2

Legend not included with this version. 
ROC Curve

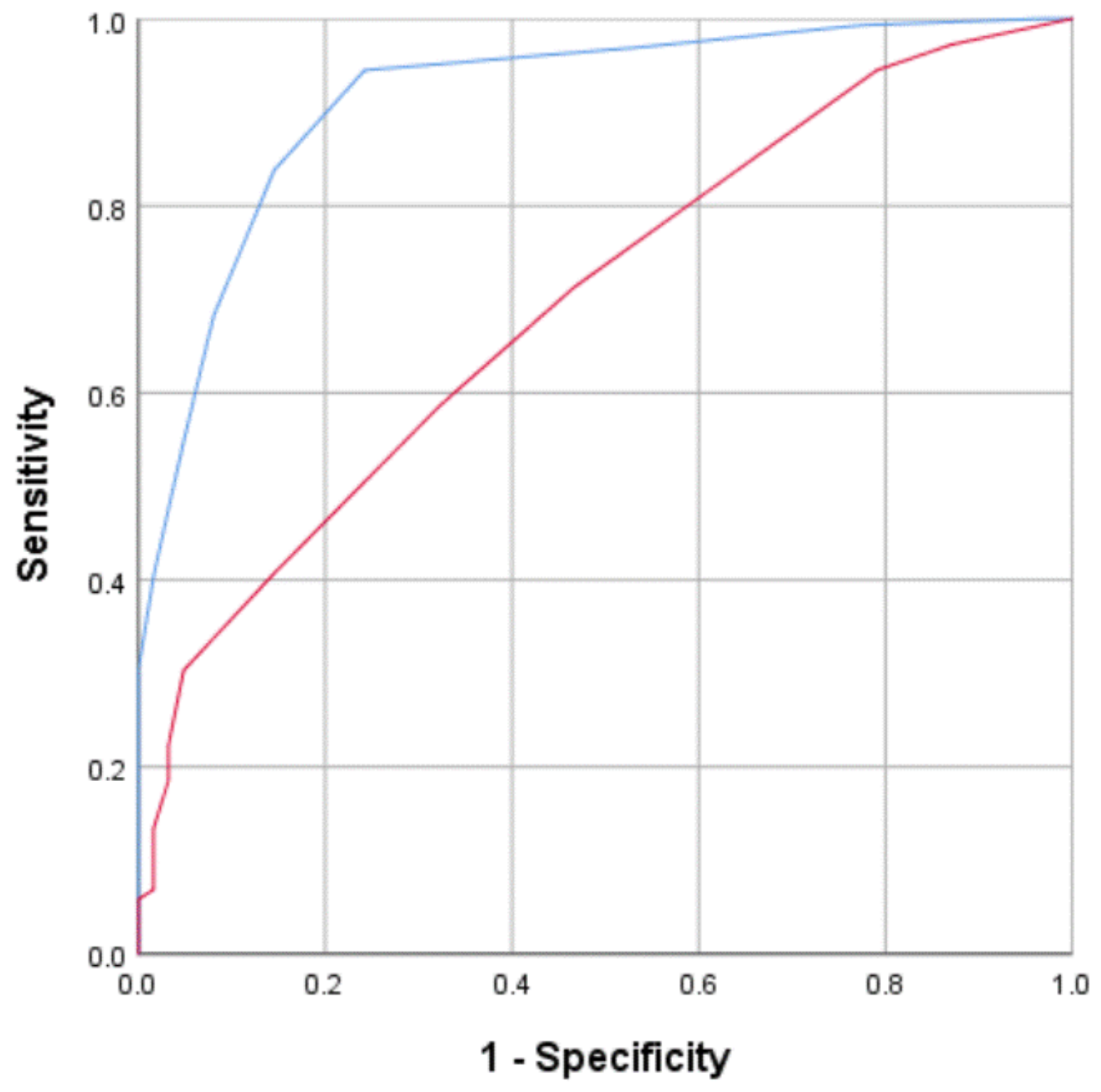

MEOWS APACHEII

\section{Figure 3}

Legend not included with this version.

\section{Supplementary Files}

This is a list of supplementary files associated with this preprint. Click to download.

- Attachedtable.jpg 